\title{
On the Zeros of the Riemann Zeta Function in the Critical Strip. IV
}

\author{
By J. van de Lune, H. J. J. te Riele and D. T. Winter
}

\begin{abstract}
Very extensive computations are reported which extend and, partly, check previous computations concerning the location of the complex zeros of the Riemann zeta function. The results imply the truth of the Riemann hypothesis for the first 1,500,000,001 zeros of the form $\sigma+i t$ in the critical strip with $0<t<545,439,823.215$, i.e., all these zeros have real part $\sigma=1 / 2$. Moreover, all these zeros are simple. Various tables are given with statistical data concerning the numbers and first occurrences of Gram blocks of various types; the numbers of Gram intervals containing $m$ zeros, for $m=0,1,2,3$ and 4; and the numbers of exceptions to "Rosser's rule" of various types (including some formerly unobserved types). Graphs of the function $Z(t)$ are given near five rarely occurring exceptions to Rosser's rule, near the first Gram block of length 9, near the closest observed pair of zeros of the Riemann zeta function, and near the largest (positive and negative) found values of $Z(t)$ at Gram points. Finally, a number of references are given to various number-theoretical implications.
\end{abstract}

1. Introduction. This paper is a continuation of three papers by Brent [1], Brent et al. [2]*, and van de Lune et al. [7]*. The computations reported there (up to $g_{300,000,000}$ ) have been extended up to $g_{1,500,000,000}$ in order to show that the first 1,500,000,001 zeros of Riemann's zeta function in the critical strip are simple and lie on the vertical with real part $1 / 2$. This establishes the truth of the Riemann hypothesis in the rectangle $\{\sigma+i t, 0<\sigma<1,0<t<545,439,823.215\}$. Moreover, parts of the computations reported on in [2] have been repeated in a slightly different manner (see below), so that it is now possible to present exact (rather than approximate) counts of the number of Gram blocks of various types and of the number of Gram intervals with various numbers of zeros, for the whole interval $\left[g_{0}, g_{1,500,000,000}\right)$.

The FORTRAN/COMPASS program described in van de Lune et al. [6], was run on a CDC CYBER 175/750 computer to separate the zeros of $Z(t)$ in the intervals $\left[g_{300,000,000}, g_{415,000,000}\right)$ and $\left[g_{1,445,000,000}, g_{1,500,000,000}\right)$. A vectorized version ([9], [14]) of that program was run on a CYBER 205 vector computer to separate the zeros of $Z(t)$ in the interval $\left[g_{415,000,000}, g_{1,445,000,000}\right)$. Finally, the program was run a little further beyond $g_{1,500,000,000}$ to yield 5 Gram blocks of lengths $1,1,2,1$ and 1 in $\left[g_{1,500,000,000}, g_{1,500,000,006}\right)$ which all satisfy Rosser's rule. Applying Theorem 3.2 of [1] we completed the proof of our claim that the first $1,500,000,001$ complex zeros of the

Received May 20, 1985.

1980 Mathematics Subject Classification. Primary 10H05; Secondary 10-04, 65E05, 30-04.

Key words and phrases. Riemann hypothesis, Riemann zeta function, Gram blocks, Rosser's rule.

* For corrections to these papers, see corrigenda section of this issue. 
Riemann zeta function have real part $1 / 2$ (and that all these zeros are simple). The total CPU time used amounted to approximately 900 hours on the CYBER 175/750 and about 1000 hours on the CYBER 205.

During the computations in the interval $\left[g_{156,800,000}, g_{200,000,000}\right)$ reported on in [2], the counts of the number of Gram blocks and of the number of Gram intervals with $0,1, \ldots$ zeros were not exact, since small shifts were made in the argument of $Z_{A}(t)$ in case the value of $Z_{A}(t)$ in a Gram point $g_{n}$ was too small to yield the correct sign of $Z\left(g_{n}\right)$ with certainty. Since all subsequent computations were carried out without shifts, i.e., $Z_{B}\left(g_{n}\right)$ was computed immediately in case $Z_{A}\left(g_{n}\right)$ was too small, we have rerun and verified our computations in the interval $\left[g_{156,800,000}, g_{200,000,000}\right)$ on the CYBER 205. The total amount of CYBER 205 CPU time needed for this check was about 21 hours.

Moreover, with the aid of our CYBER 205 program we checked some of the computations reported on in [1] and [7], viz., those concerning the intervals $\left[g_{1,000}, g_{5,000,000}\right)$ and $\left[g_{200,000,000}, g_{210,000,000}\right)$. We found exact agreement with the corresponding results in [1] and [7]. The CPU time needed on the CYBER 205 was about 2800 seconds and 5 hours, respectively.

2. Computation of $Z(t)$ and Error Analysis. In principle, our method of computing $Z(t)$ is exactly as described in [6] and Section 3 of [2]. In order to run our program on the CYBER 205, the most time-consuming part of our FORTRAN/COMPASS CYBER $175 / 750$ program, i.e., the summation of $\sum_{k=1}^{m} k^{-1 / 2} \cos [t \cdot \log (k)-\theta(t)]$ in $Z_{A}(t)$ (cf. [1], formula (2.6)), was vectorized by invoking so-called Q8-calls. Details are given in [9] and [14]. As a result, our CYBER 205 program ran about 7 times as fast as the CYBER 175/750 version.

In [6] we have given a rigorous error analysis of our computation of $Z(t)$ on the

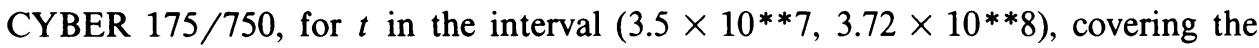
range of zero \#81,000,000 to zero \#1,000,000,000 of $\zeta(s)$ in the critical strip. In Section 3 of [2], the resulting bounds for the error in the computed value $\tilde{Z}(t)$ of $Z(t)$ are given for methods A and B.

For the computations reported in the present paper, we have extended this error analysis to the interval $\left(3.5 \times 10^{* *} 7,5.6 \times 10^{* * 8}\right)$, in order to cover the range of zero \# 81,000,000 to zero \#1,500,000,000, both for the CYBER 175/750 and the CYBER 205 (several spot checks of the CYBER 205 computations were carried out on the CYBER 175/750). For the CYBER 205 we took into account that the singleand double-precision floating-point arithmetic works with 47- and 94-bit binary fractions, respectively. Since this machine works with truncated arithmetic, we took $\varepsilon_{S}=2^{* *}(-46)$ and $\varepsilon_{D}=2^{* *}(-93)$ in our error analysis (cf., [6, p. 12]). This analysis is completely analogous to the one given in [6] and rather tedious. Therefore, we omit the details. The dominant terms in the upper bounds for the errors are, in the case of method A, the error caused by the interpolation in the cosine table, and, in the case of method B, the inherent error caused by using the Riemann-Siegel formula with the first two terms of its asymptotic expansion. These two terms do not depend on the computer used. The other, nondominant, terms are quite small compared with the dominant terms. For both our CYBER 205 and our CYBER 
$175 / 750$ programs we found the following bounds for the error in the computed value $\tilde{Z}(t)$ of $Z(t)$ :

$$
|\tilde{Z}(t)-Z(t)|< \begin{cases}3 \times 10^{* *}(-7) \tau^{1 / 4} & \text { for method A, } \\ 5.5 \times 10^{* *}(-3) \tau^{-5 / 4} & \text { for method B }\end{cases}
$$

for any $t(=2 \pi \tau)$ in the interval $\left(3.5 \times 10^{* * 7}, 5.6 \times 10^{* * 8}\right)$. A safe upper bound for this error is $3 \times 10^{* *}(-5)$ for method A and $2.1 \times 10^{* *}(-11)$ for method $\mathrm{B}$. In our program we actually used the very conservative fixed bounds $10^{* *}(-4)$ and $2.5 \times 10^{* *}(-7)$, respectively. Not a single Gram point was found for which method B could not determine the sign of $Z(t)$.

3. Statistics. Here we present, for the whole interval $\left[g_{0}, g_{1,500,000,000}\right)$, some statistics concerning Gram blocks, the number of zeros in Gram intervals and the exceptions to Rosser's rule (summarizing the statistics up to $g_{300,000,000}$ given in [1], [2] and [7]). As stated already in Section 1, the counts given here are exact, since no shifts were made when computing $Z(t)$ in the Gram points.

Table 1 gives the number of Gram blocks of length $\leqslant 9$ in the interval $\left[g_{0}, g_{1,500,000,000}\right)$ for strings of $10 * * 8$ successive Gram intervals. The last line gives the totals for the whole interval. The average Gram block length is 1.2089. The number of Gram blocks of length 1 is slowly decreasing, whereas the number of Gram blocks of length $\geqslant 2$ is increasing.

In Table 2 we list the number of Gram blocks of type $(j, k), 1 \leqslant j \leqslant 9$, $1 \leqslant k \leqslant j$, in the interval $\left[g_{0}, g_{1,500,000,000}\right)$, as far as they can be classified according to the definition given in $[1$, p. 1370]. The numbers in parentheses denote the percentages of the totals given in Table 1. We also specify the number of Gram blocks of lengths 2 and 3 which cannot be classified, viz., those of length 2 with " 0 0" and " 2 2" zero-pattern, and those of length 3 with "0 10 ", "2 30 " and "0 32 " zero-pattern. These, very rare, Gram blocks occur in relation to exceptions to Rosser's rule (see below).

TABLE 1

Number of Gram blocks of given length $k$ :

$$
J^{\prime}(k, n)=J(k, n+10 * * 8)-J(k, n)
$$

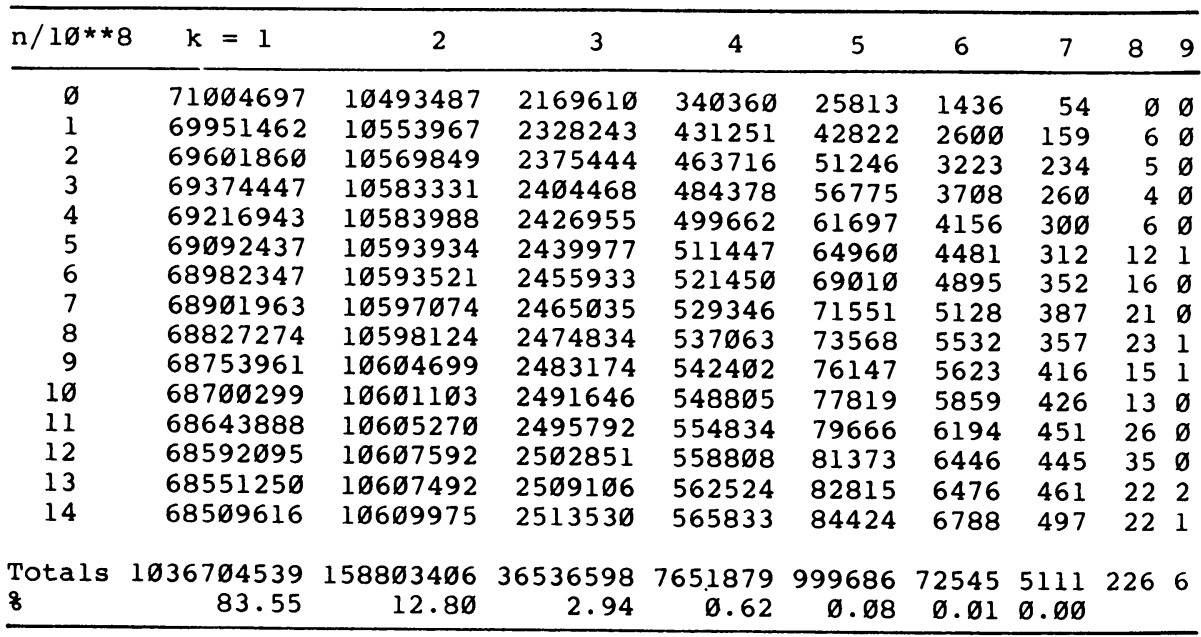


TABLE 2

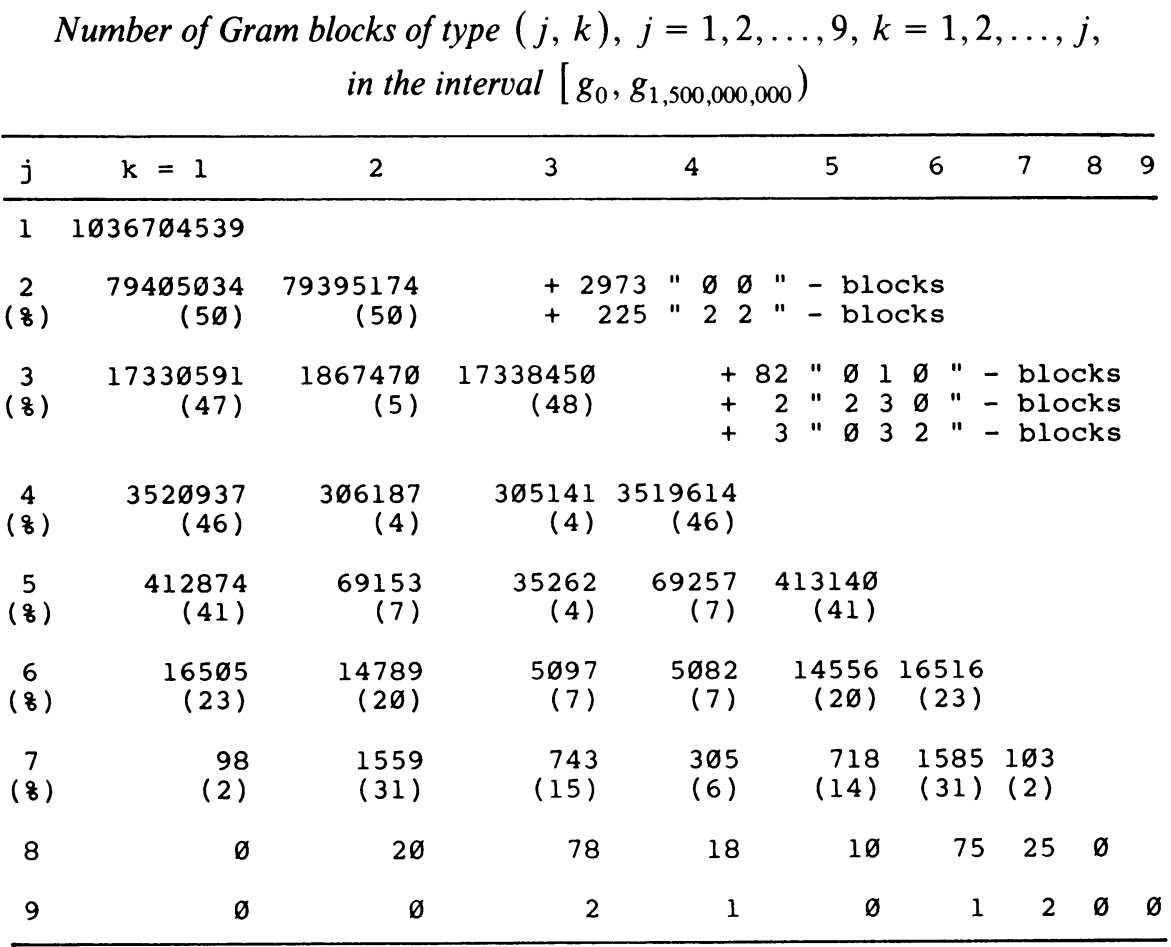

The tendency of the so-called "missing two zeros" (cf., [2, Section 2]) in Gram blocks of lengths $\geqslant 3$ and $\leqslant 6$ to lie in one of the two outer Gram intervals of the Gram block is partly illustrated by Table 3 . This table gives the number of Gram blocks of lengths 4,5 and 6 in 3 strings of $10 * * 8$ Gram intervals, viz., [ $g_{0}, g_{100,000,000}$ ), $\left[g_{700,000,000}, g_{800,000,000}\right)$ and $\left[g_{1,400,000,000}, g_{1,500,000,000}\right)$. For Gram blocks of lengths $\geqslant 3$ and $\leqslant 6$ the distribution of the various types seems to tend to a certain limit which seems to be fairly well reached in the third string. For Gram blocks of length $\geqslant 7$, however, our numbers are probably still too small to supply any evidence for the existence of a limit distribution (although we are tempted to believe that such distributions exist for Gram blocks of all lengths).

Table 4 (which partly summarizes previous such tables in [1] and [2]) gives the first occurrences of the various types of Gram blocks which have been found. Note the rather "late" first occurrence of type $(8,4)$ and $(8,5)$ Gram blocks and the absence of type $(8,1)$ and $(8,8)$ blocks and of blocks of length 9 of various types.

Table 5 shows the number of Gram intervals which contain exactly $0,1, \ldots$ zeros, for strings of $10 * * 8$ Gram intervals. In three cases, the index of the last Gram point of a string (and of the first Gram point of the next string) is not a multiple of $10 * * 8$ since this index corresponds to a "bad" Gram point. In these cases, the string was extended up to the first "good" Gram point after the bad Gram point. As a partial check of the counts in this table the following relation is useful (this follows from a simple counting argument concerning the zeros in consecutive Gram intervals): if $i_{j}$ is the number of Gram intervals with $j$ zeros, in a given string of Gram blocks $\left[g_{n 1}, g_{n 2}\right.$ ) which contains $n 2-n 1$ zeros of $Z(t)$, such that missing pairs of zeros connected with exceptions to Rosser's rule have "crossed" neither the Gram point 
TABLE 3

Number of Gram blocks of type $(j, k), j=4,5,6, k=1,2, \ldots, j$, in the intervals $\left[g_{n \times 10^{* * 8}}, g_{(n+1) \times 10^{* * 8}}\right)$, for $n=0,7$ and 14

\begin{tabular}{|c|c|c|c|c|c|c|c|c|}
\hline$j$ & $\mathrm{n}$ & total & $k=1$ & 2 & 3 & 4 & 5 & 6 \\
\hline \multirow[t]{3}{*}{4} & $\emptyset$ & $\begin{array}{r}340360 \\
(8)\end{array}$ & $\begin{array}{c}152448 \\
(45)\end{array}$ & $\begin{array}{r}17793 \\
(5)\end{array}$ & $\begin{array}{r}17972 \\
(5)\end{array}$ & $\begin{array}{r}152147 \\
(45)\end{array}$ & & \\
\hline & 7 & $\begin{array}{r}529346 \\
(8)\end{array}$ & $\begin{array}{r}243856 \\
(46)\end{array}$ & $\begin{array}{r}20724 \\
(4)\end{array}$ & $\begin{array}{r}20649 \\
(4)\end{array}$ & $\begin{array}{r}244117 \\
(46)\end{array}$ & & \\
\hline & 14 & $\begin{array}{r}565833 \\
(8)\end{array}$ & $\begin{array}{r}261995 \\
(46)\end{array}$ & $\begin{array}{r}21151 \\
(4)\end{array}$ & $\begin{array}{r}20879 \\
(4)\end{array}$ & $\begin{array}{r}261808 \\
(46)\end{array}$ & & \\
\hline \multirow[t]{3}{*}{5} & $\emptyset$ & $\begin{array}{r}25813 \\
(8)\end{array}$ & $\begin{array}{l}8549 \\
(33)\end{array}$ & $\begin{array}{l}3570 \\
(14)\end{array}$ & $\begin{array}{r}1579 \\
(6)\end{array}$ & $\begin{array}{l}3539 \\
(14)\end{array}$ & $\begin{array}{l}8576 \\
(33)\end{array}$ & \\
\hline & 7 & $\begin{array}{r}71551 \\
(8)\end{array}$ & $\begin{array}{r}29813 \\
(42)\end{array}$ & $\begin{array}{r}4779 \\
(7)\end{array}$ & $\begin{array}{r}2452 \\
(3)\end{array}$ & $\begin{array}{r}4698 \\
(7)\end{array}$ & $\begin{array}{r}29809 \\
(42)\end{array}$ & \\
\hline & 14 & $\begin{array}{r}84424 \\
(8)\end{array}$ & $\begin{array}{r}35934 \\
(43)\end{array}$ & $\begin{array}{r}4892 \\
(6)\end{array}$ & $\begin{array}{r}2651 \\
(3)\end{array}$ & $\begin{array}{r}4930 \\
(6)\end{array}$ & $\begin{array}{r}36017 \\
(43)\end{array}$ & \\
\hline \multirow[t]{3}{*}{6} & $\emptyset$ & $\begin{array}{r}1436 \\
(8)\end{array}$ & $\begin{array}{r}93 \\
(6)\end{array}$ & $\begin{array}{r}473 \\
(33)\end{array}$ & $\begin{array}{l}157 \\
(11)\end{array}$ & $\begin{array}{l}129 \\
(9)\end{array}$ & $\begin{array}{r}518 \\
(36)\end{array}$ & $\begin{array}{r}66 \\
(5)\end{array}$ \\
\hline & 7 & $\begin{array}{r}5128 \\
(8)\end{array}$ & $\begin{array}{l}1166 \\
(23)\end{array}$ & $\begin{array}{l}1042 \\
(2 \varnothing)\end{array}$ & $\begin{array}{l}339 \\
(7)\end{array}$ & $\begin{array}{l}348 \\
(7)\end{array}$ & $\begin{array}{l}10 \varnothing 6 \\
(2 \varnothing)\end{array}$ & $\begin{array}{l}1227 \\
(24)\end{array}$ \\
\hline & 14 & $\begin{array}{r}6788 \\
(8)\end{array}$ & $\begin{array}{l}1875 \\
(28)\end{array}$ & $\begin{array}{l}1121 \\
(17)\end{array}$ & $\begin{array}{l}415 \\
(6)\end{array}$ & $\begin{array}{l}400 \\
(6)\end{array}$ & $\begin{array}{l}1114 \\
(16)\end{array}$ & $\begin{array}{l}1863 \\
(27)\end{array}$ \\
\hline
\end{tabular}

TABLE 4

First occurrences of Gram blocks of various types

\begin{tabular}{|c|c|c|c|c|c|}
\hline j & $\mathrm{k}$ & $\mathrm{n}$ & j & $\mathrm{k}$ & $\mathrm{n}$ \\
\hline 2 & 1 & 133 & 7 & 1 & $258,779,892$ \\
\hline \multirow[t]{2}{*}{2} & 2 & 125 & 7 & 2 & $13,869,654$ \\
\hline & & & 7 & 3 & $17,121,221$ \\
\hline 3 & 1 & 3,356 & 7 & 4 & $37,091,042$ \\
\hline 3 & 2 & 2,144 & 7 & 5 & $20,641,464$ \\
\hline \multirow[t]{2}{*}{3} & 3 & 4,921 & 7 & 6 & $52,266,282$ \\
\hline & & & 7 & 7 & $195,610,937$ \\
\hline 4 & 1 & 83,701 & & & \\
\hline 4 & 2 & 39,889 & 8 & 2 & $112,154,948$ \\
\hline 4 & 3 & 18,243 & 8 & 3 & $175,330,804$ \\
\hline \multirow[t]{2}{*}{4} & 4 & 67,433 & 8 & 4 & $717,574,239$ \\
\hline & & & 8 & 5 & $454,025,825$ \\
\hline 5 & 1 & $1,833,652$ & 8 & 6 & $145,659,810$ \\
\hline 5 & 2 & $243, \emptyset 21$ & 8 & 7 & $165,152,519$ \\
\hline 5 & 3 & 601,944 & & & \\
\hline 5 & 4 & 68,084 & 9 & 3 & $542,964,969$ \\
\hline 5 & 5 & 455,256 & 9 & 4 & $1,331,284,715$ \\
\hline & & & 9 & 6 & $978,739,921$ \\
\hline 6 & 1 & $20,046,223$ & 9 & 7 & $818,033,831$ \\
\hline 6 & 2 & $2,656,216$ & & & \\
\hline 6 & 3 & $4,718,714$ & & & \\
\hline 6 & 4 & $1,181,229$ & & & \\
\hline 6 & 5 & $2,842,089$ & & & \\
\hline 6 & 6 & $19,986,469$ & & & \\
\hline
\end{tabular}


TABLE 5

Number of Gram intervals in $\left[g_{n 1}, g_{n 2}\right)$ containing exactly m zeros

\begin{tabular}{|c|c|c|c|c|c|c|c|}
\hline $\mathrm{nl}$ & $\mathrm{n} 2$ & $m=\emptyset$ & $m=1$ & $m=2$ & $m=3$ & $m=$ & $=4$ \\
\hline$\emptyset$ & 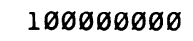 & 13197331 & 73771910 & 12864188 & $16657 \varnothing$ & 1 & 1 \\
\hline $1000 \emptyset \emptyset \emptyset \emptyset \emptyset$ & $2 \varnothing \varnothing \emptyset \emptyset \emptyset \emptyset \emptyset \emptyset$ & 13534327 & 73106626 & 13183768 & 175278 & 1 & 1 \\
\hline $2 \varnothing \varnothing \varnothing \emptyset \emptyset \emptyset \emptyset \emptyset$ & 300000000 & 13641172 & 72895112 & 13286261 & 177454 & 1 & 1 \\
\hline $3 \varnothing 00 \emptyset 0 \varnothing \emptyset \emptyset$ & 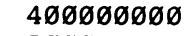 & 13711578 & 72755501 & 13354267 & 178651 & 3 & 3 \\
\hline $4 \varnothing \varnothing \varnothing \varnothing \varnothing \varnothing \varnothing \varnothing$ & 500000001 & 13756913 & 72666325 & 13396614 & 180148 & 1 & 1 \\
\hline $5 \varnothing \varnothing \varnothing \varnothing \emptyset \emptyset \emptyset 1$ & 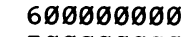 & 13795033 & 72589842 & 13435215 & 179909 & $\emptyset$ & $\gamma$ \\
\hline 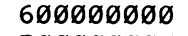 & 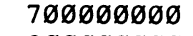 & 13826622 & 72528206 & 13463727 & 181440 & 5 & 5 \\
\hline $7 \varnothing \varnothing \varnothing \varnothing \varnothing \varnothing \varnothing \varnothing$ & 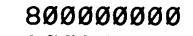 & 13849738 & 72481722 & 13487344 & 181194 & & 2 \\
\hline $8 \emptyset \emptyset \emptyset \emptyset \emptyset \emptyset \emptyset \emptyset$ & 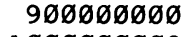 & 13871424 & 72439079 & 13507575 & 181917 & & 5 \\
\hline 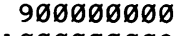 & 1000000003 & 13894145 & 72393385 & 13530805 & 181664 & & 4 \\
\hline 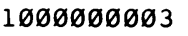 & 1100000001 & 13908465 & 72365865 & 13542874 & 182791 & & 3 \\
\hline $110 \varnothing \varnothing \varnothing \varnothing \varnothing \varnothing 1$ & $12 ø \varnothing \emptyset \emptyset \emptyset \emptyset \emptyset \emptyset$ & 13924978 & 72332789 & 13559487 & 182744 & & 1 \\
\hline 1200000000 & 1300000000 & 13940406 & 72302046 & 13574692 & 182854 & & 2 \\
\hline 1300000000 & $14000000 \varnothing \emptyset$ & 13952735 & 72278368 & 13585060 & 183836 & & 1 \\
\hline 1400000000 & $150 \varnothing \varnothing \varnothing \varnothing \varnothing \varnothing \varnothing$ & 13964556 & 72254377 & 13597581 & 183483 & & 3 \\
\hline$\emptyset$ & $15 \varnothing \varnothing \varnothing \varnothing \emptyset \emptyset \emptyset \emptyset$ & $\begin{array}{r}206769423 \\
13.78\end{array}$ & $\begin{array}{r}1089161153 \\
72.61\end{array}$ & $\begin{array}{r}201369458 \\
13.42\end{array}$ & $\begin{array}{r}2699933 \\
0.18\end{array}$ & 33 & 3 \\
\hline
\end{tabular}

$g_{n 1}$ nor $g_{n 2}$, then we have $i_{0}=\sum_{j \geqslant 2} j \cdot i_{j}$. Note that the number of Gram intervals with precisely one zero is slowly (and monotonically) decreasing, whereas the number of Gram intervals with 0, 2, 3 and 4 zeros is increasing.

We have found 3055 exceptions to Rosser's rule (2973 of length 2 and 82 of length 3 ), including some formerly unknown types. Table 6 surveys the various types of exceptions which have been found so far (note that a length 2, type 10 exception has been defined, but not yet found). For all 3055 exceptions, the missing two zeros were located either in the preceding or in the succeeding Gram block (which always had length $\leqslant 3$ ). Our main separation program did not search for the missing two zeros in adjacent Gram blocks: this was done afterwards with an interactive program. Future investigators may find it useful to implement this search in their main separation program. The simplest case where this would not be successful is given by the zero-pattern "0 013 " (or "3 1000 "), i.e., a Gram block of length 2 without any zeros followed (or preceded) by two Gram blocks of length 1, the nearest containing 1 and the other 3 zeros. We do not have the slightest idea where this phenomenon might possibly occur for the first time.

Table 7 gives the frequencies of the exceptions to Rosser's rule in strings of $10 * * 8$ successive Gram intervals. Note the gradual, although not monotonic, increase of the number of exceptions of length 2 of types 1, 2, 5 and 6. For all 3055 exceptions, we have computed the local extreme values of $S(t)$ (cf., [1, p. 1370]) near these exceptions.

Table 8 lists those exceptions for which the corresponding local extreme values exceed 2.2 for length 2 , and 2.1 for length 3 exceptions. The most extreme values in this table are marked by an asterisk. It should be noted that, by a different method, Karkoschka and Werner [3] have found 10 of the 21 exceptions to Rosser's rule in the interval $\left[g_{1,000,000,000}, g_{1,100,000,000}\right)$ for which $\left|S_{\text {extr }}\right|>2.1$ (including those three for which $\left|S_{\text {extr }}\right|>2.2$ ).

In Table 9 we give frequency counts of those exceptions for which the $\left|S_{\text {extr }}\right|$-values lie beyond 2 , in intervals of length 0.05 , for three groups of 1000 successive exceptions. There is a tendency of the extreme values to increase, albeit very slowly. 
TABLE 6

Various types of exceptions to Rosser's rule and their frequencies in $\left[g_{0}, g_{1,500,000,000}\right)$

\begin{tabular}{|c|c|c|c|c|c|c|c|c|c|c|}
\hline LEN & $\Gamma \mathrm{H}=2$ & & $\sqrt{\begin{array}{l}\text { Gram } \\
\text { of le } \\
\text { with } \\
\text { zero- }\end{array}}$ & $\begin{array}{l}\text { lock } \\
\text { gth } 2 \\
\emptyset \emptyset " \\
\text { attern }\end{array}$ & & & & & & \\
\hline$g_{n-3}$ & $g_{n-2}$ & $g_{n-1}$ & $\mathrm{~g}_{\mathrm{n}}$ & $g_{n+1}$ & $g_{n+2}$ & $g_{n+3}$ & $g_{n+4}$ & $g_{n+5}$ & type & $\begin{array}{l}\text { freq } \\
\text { (note) }\end{array}$ \\
\hline$\emptyset$ & $\begin{array}{l}\emptyset \\
2 \\
3\end{array}$ & $\begin{array}{l}3 \\
4 \\
2 \\
2\end{array}$ & $\begin{array}{l}\emptyset \\
\emptyset \\
\emptyset \\
\emptyset \\
\emptyset \\
\emptyset \\
\emptyset \\
\emptyset \\
\emptyset \\
\emptyset\end{array}$ & $\begin{array}{l}\emptyset \\
\emptyset \\
\emptyset \\
\emptyset \\
\emptyset \\
\emptyset \\
\emptyset \\
\emptyset \\
\emptyset \\
\emptyset\end{array}$ & $\begin{array}{l}3 \\
4 \\
2\end{array}$ & 3 & $\emptyset$ & & $\begin{array}{r}1 \\
2 \\
3 \\
4 \\
5 \\
6 \\
7 \\
8 \\
9 \\
10\end{array}$ & 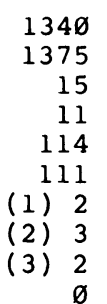 \\
\hline
\end{tabular}

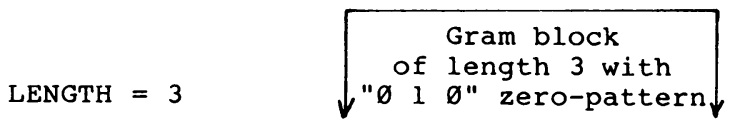

$$
\begin{aligned}
& g_{n-2} \quad g_{n-1} \quad g_{n} \quad g_{n+1} \quad g_{n+2} \quad g_{n+3} \quad g_{n+4} \quad g_{n+5} \text { type freq. }
\end{aligned}
$$

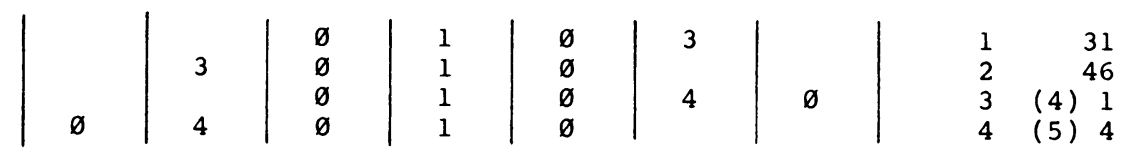

Notes ${ }_{n}$ for $n=$
(1)
(2)
(3)
(4)
$1,070,232,754$
$526,196,236$
$983,377,342$
$744,719,566$
$368,714,78 \emptyset$
$1,368, \varnothing 02,233$
$750,375,860$
$1,209,834,868$
$, 257,209,100$
$437,953,501 \quad 958,241,934 \quad 1,003,780,082$

In Figures 1-5 we present graphs of the function $Z(t)$ near the first exceptions to Rosser's rule of length 2, types 7, 8 and 9, and length 3, types 3 and 4, respectively. The number of zeros in Gram intervals is indicated in parentheses. The scale of the graphs does not allow the reader to "see" all zeros, but sufficient magnification of the graphs (as in [7]) would resolve these zeros without any difficulties. The local extreme values of $S(t)$ near these exceptions are $-2.033411,2.092910,-2.060040$, -2.012663 and 2.012380 , respectively.

Figure 6 shows $B_{542,964,969}$, the first Gram block of length 9 (which is of type $(9,3))$.

Figure 7 presents a graph of $Z(t)$ in the Gram block $B_{1,048,449,112}$ of length 2 and of type $(2,1)$. This Gram block contains the closest pair of zeros observed by us. Comparing their distance with the quantity $2 \pi / \log \left(t_{n}\right)$ which is a natural measure for the distance of two consecutive zeros $t_{n}$ and $t_{n+1}$ of $Z(t)$, we have

$$
\left(t_{n+1}-t_{n}\right) \log \left(t_{n}\right) / 2 \pi \cong 0.00034
$$


TABLE 7

Number of exceptions to Rosser's rule in the intervals

$\left[g_{n}, g_{n+100,000,000}\right)$ for $n=0(100,000,000) 1,400,000,000$

\begin{tabular}{|c|c|c|c|c|c|c|c|c|c|c|c|c|c|c|}
\hline \multirow[b]{2}{*}{$\mathrm{n} / 10 * * 8$} & \multicolumn{3}{|c|}{$\begin{array}{l}<---------- \\
\text { TYPE }\end{array}$} & - LENGTH & $1=2$ & $2-$ & \multirow[b]{2}{*}{7} & \multirow[b]{2}{*}{8} & \multirow[b]{2}{*}{9} & \multirow[b]{2}{*}{10} & \multicolumn{4}{|c|}{$\begin{array}{l}\langle- \text { LENGTH }=3-> \\
\text { TYPE }\end{array}$} \\
\hline & 1 & 2 & 3 & 4 & 5 & 6 & & & & & 1 & 2 & 3 & 4 \\
\hline$\varnothing$ & 15 & 9 & 1 & $\emptyset$ & $\emptyset$ & $\emptyset$ & $\emptyset$ & $\emptyset$ & $\emptyset$ & $\emptyset$ & $\theta$ & $\emptyset$ & $\emptyset$ & $\emptyset$ \\
\hline 1 & 37 & 38 & 1 & $\emptyset$ & 1 & 2 & $\emptyset$ & $\emptyset$ & $\emptyset$ & $\emptyset$ & $\emptyset$ & $\varnothing$ & $\emptyset$ & $\emptyset$ \\
\hline 2 & 52 & 68 & $\varnothing$ & 1 & 3 & 2 & $\emptyset$ & $\emptyset$ & $\varnothing$ & $\emptyset$ & 2 & 1 & $\emptyset$ & $\emptyset$ \\
\hline 3 & 53 & 77 & 2 & $\bar{\emptyset}$ & 3 & 2 & $\theta$ & $\emptyset$ & $\emptyset$ & $\emptyset$ & 3 & 2 & $\emptyset$ & 1 \\
\hline 4 & 79 & 78 & $\emptyset$ & $\emptyset$ & 5 & 3 & $\emptyset$ & $\emptyset$ & $\emptyset$ & $\emptyset$ & 1 & $\theta$ & $\emptyset$ & 1 \\
\hline 5 & 94 & 71 & $\emptyset$ & $\varnothing$ & 7 & 5 & $\emptyset$ & 1 & $\emptyset$ & $\emptyset$ & 2 & 5 & $\emptyset$ & $\emptyset$ \\
\hline 6 & 82 & $10 \varnothing$ & 4 & 1 & 8 & 12 & $\emptyset$ & $\emptyset$ & $\emptyset$ & $\theta$ & 1 & 3 & $\emptyset$ & $\emptyset$ \\
\hline 7 & 104 & 98 & 1 & $\varnothing$ & 6 & 7 & $\emptyset$ & 1 & $\emptyset$ & $\emptyset$ & 2 & 2 & 1 & $\emptyset$ \\
\hline 8 & 98 & $1 ø 8$ & 1 & 4 & 7 & 7 & $\emptyset$ & $\emptyset$ & $\emptyset$ & $\emptyset$ & 3 & 4 & $\emptyset$ & $\emptyset$ \\
\hline 9 & 107 & 115 & 1 & 1 & 11 & 13 & $\emptyset$ & $\emptyset$ & 1 & $\emptyset$ & 2 & 4 & $\emptyset$ & 1 \\
\hline 10 & 121 & 100 & 1 & 1 & 11 & 8 & 1 & $\emptyset$ & $\emptyset$ & $\emptyset$ & 5 & 2 & $\emptyset$ & 1 \\
\hline 11 & 112 & 132 & $\emptyset$ & 1 & 15 & 7 & $\emptyset$ & $\theta$ & $\emptyset$ & $\emptyset$ & 2 & 8 & $\emptyset$ & $\emptyset$ \\
\hline 12 & 130 & 135 & 1 & $\emptyset$ & 12 & 13 & $\emptyset$ & 1 & 1 & $\emptyset$ & 3 & 1 & $\emptyset$ & $\emptyset$ \\
\hline 13 & 128 & 123 & $\emptyset$ & 1 & 17 & 14 & 1 & $\emptyset$ & $\emptyset$ & $\emptyset$ & 2 & 8 & $\emptyset$ & $\emptyset$ \\
\hline 14 & 128 & 123 & 2 & 1 & 8 & 16 & $\varnothing$ & $\emptyset$ & $\emptyset$ & $\emptyset$ & 3 & 6 & $\emptyset$ & $\emptyset$ \\
\hline Totals & 1340 & 1375 & 15 & 11 & 114 & 111 & 2 & 3 & 2 & $\emptyset$ & 31 & 46 & 1 & 4 \\
\hline
\end{tabular}

TABLE 8

Exceptions to Rosser's rule for which the absolute local extreme value of $S(t)$ exceeds 2.2 (length 2 ) resp. 2.1 (length 3 )

\begin{tabular}{|c|c|c|c|c|c|c|}
\hline $\begin{array}{r}\text { Nota } \\
\text { where }\end{array}$ & $\begin{array}{l}\text { tion: } \\
\mathrm{n} \text { is the }\end{array}$ & $\begin{array}{l}n \text { (type } \\
\text { index of }\end{array}$ & $\begin{array}{l}\text { ) extreme value } \\
\text { the Gram block }\end{array}$ & of & $\begin{array}{l}s(t) \text { close } \\
\text { containing }\end{array}$ & $\begin{array}{l}\text { e to } \text { B }^{\prime} \\
\text { no zeros }\end{array}$ \\
\hline & LENGTH $=$ & & 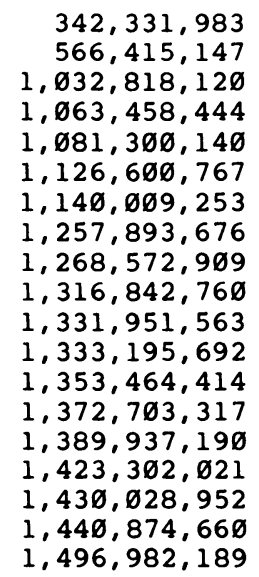 & $\begin{array}{l}(2) \\
(1) \\
(1) \\
(1) \\
(1) \\
(2) \\
(1) \\
(1) \\
(2) \\
(2) \\
(1) \\
(2) \\
(1) \\
(1) \\
(2) \\
(5) \\
(2) \\
(1) \\
(1)\end{array}$ & 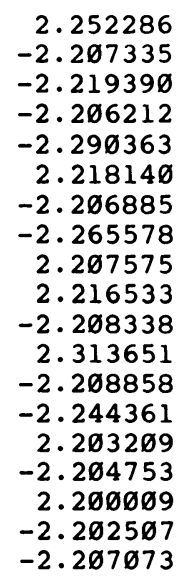 & $\star$ \\
\hline & LENGTH $=$ & 3 & $\begin{array}{l}1,689,751,985 \\
1,339,212,674\end{array}$ & $\begin{array}{l}(1) \\
(2)\end{array}$ & $\begin{array}{r}-2.122474 \\
2.106224\end{array}$ & \\
\hline
\end{tabular}




\section{TABLE 9}

Distribution of absolute local extreme values of $S(t)$, beyond 2, in intervals $[S 1, S 2)$ of length 0.05

\begin{tabular}{|c|c|c|c|c|c|c|c|c|}
\hline $\begin{array}{l}\text { exception } \\
\text { numbers }\end{array}$ & $\begin{array}{l}\text { S1 } \\
\text { s2 }\end{array}$ & $\begin{array}{l}=2 . \emptyset \emptyset \\
=2 . \emptyset 5\end{array}$ & $\begin{array}{l}2.05 \\
2.10\end{array}$ & $\begin{array}{l}2.10 \\
2.15\end{array}$ & $\begin{array}{l}2.15 \\
2.20\end{array}$ & $\begin{array}{l}2.20 \\
2.25\end{array}$ & $\begin{array}{l}2.25 \\
2.30\end{array}$ & $\begin{array}{l}2.30 \\
2.35\end{array}$ \\
\hline $\begin{array}{r}1-1 \emptyset \emptyset \emptyset \\
1 \emptyset \emptyset 1-2 \emptyset \emptyset \emptyset \\
2 \emptyset \emptyset 1-3 \emptyset \emptyset \emptyset\end{array}$ & & $\begin{array}{l}728 \\
681 \\
673\end{array}$ & $\begin{array}{l}193 \\
228 \\
215\end{array}$ & $\begin{array}{l}67 \\
66 \\
83\end{array}$ & $\begin{array}{l}10 \\
21 \\
17\end{array}$ & $\begin{array}{r}1 \\
3 \\
10\end{array}$ & $\begin{array}{l}1 \\
1 \\
1\end{array}$ & $\begin{array}{l}0 \\
0 \\
1\end{array}$ \\
\hline
\end{tabular}

The corresponding value for the two close zeros found by Brent [1, p. 1371] is about 0.0014 .

Our program kept track of large values of $Z(t)$ in Gram points. The largest positive and negative values found are: $Z\left(g_{1,211,024,724}\right) \cong 116.88$ and $Z\left(g_{1,381,150,789}\right)$ $\cong-116.147$. Figures 8 and 9 show the graphs of $Z(t)$ near these extrema. Figure 8 shows a Gram block of length 4 with " 21110 " zero-pattern followed by a Gram block of length 3 with " 012 " zero-pattern. The large value of $Z$ lies in the common point of the two Gram blocks. Note that this graph shows two zeros which have a distance of approximately 3.85 times the current length of a Gram interval (which is, locally, almost constant). Figure 9 shows a Gram block of length 2 with " 00 " zero-pattern (this is an exception to Rosser's rule of length 2, type 2; the missing two zeros are located in the Gram interval preceding this block) followed by a Gram block of length 4 with "0 1112 " zero-pattern. Here, the two zeros before and after the extreme value of $Z$ have a distance of approximately 3.65 times the current length of a Gram interval.

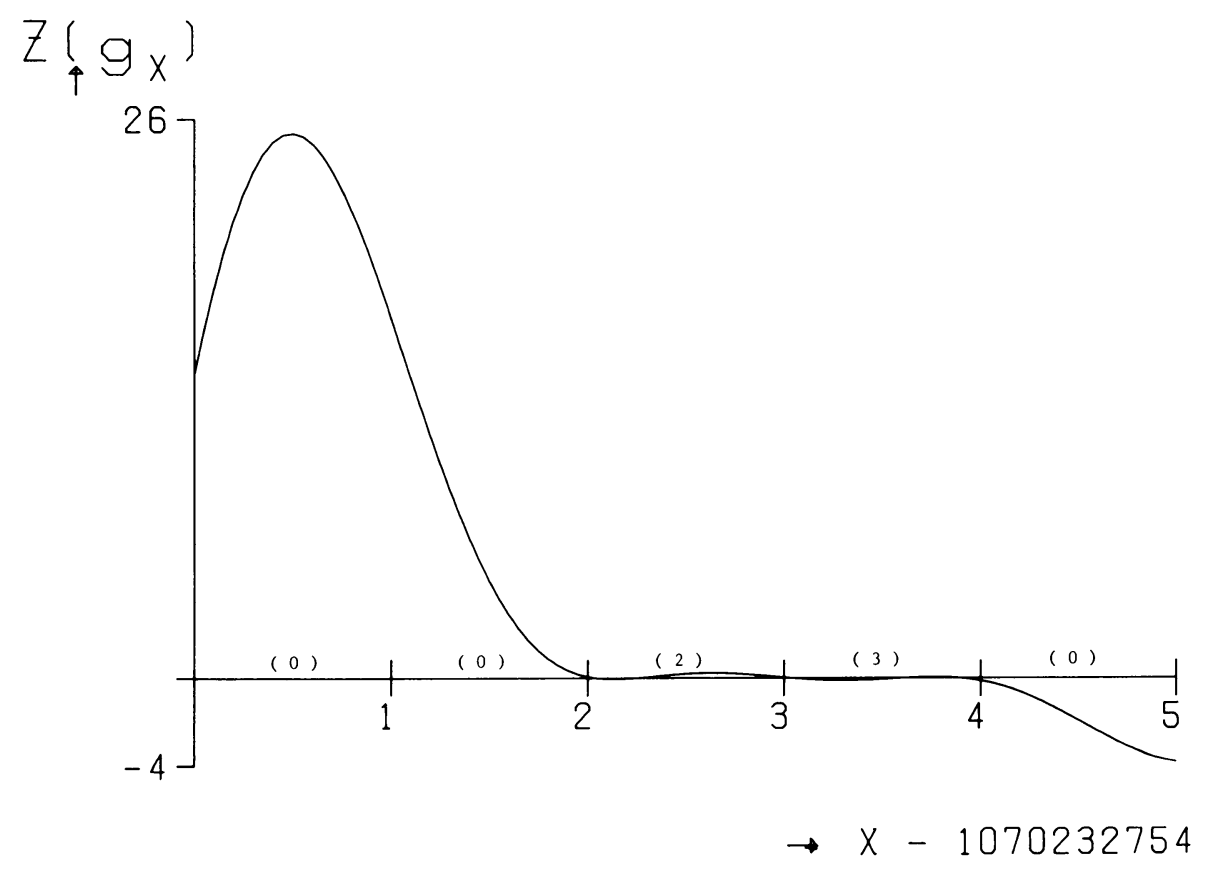

FIGURE 1

$B_{1,070,232,754}$, the first exception to Rosser's rule of length 2 , type 7 


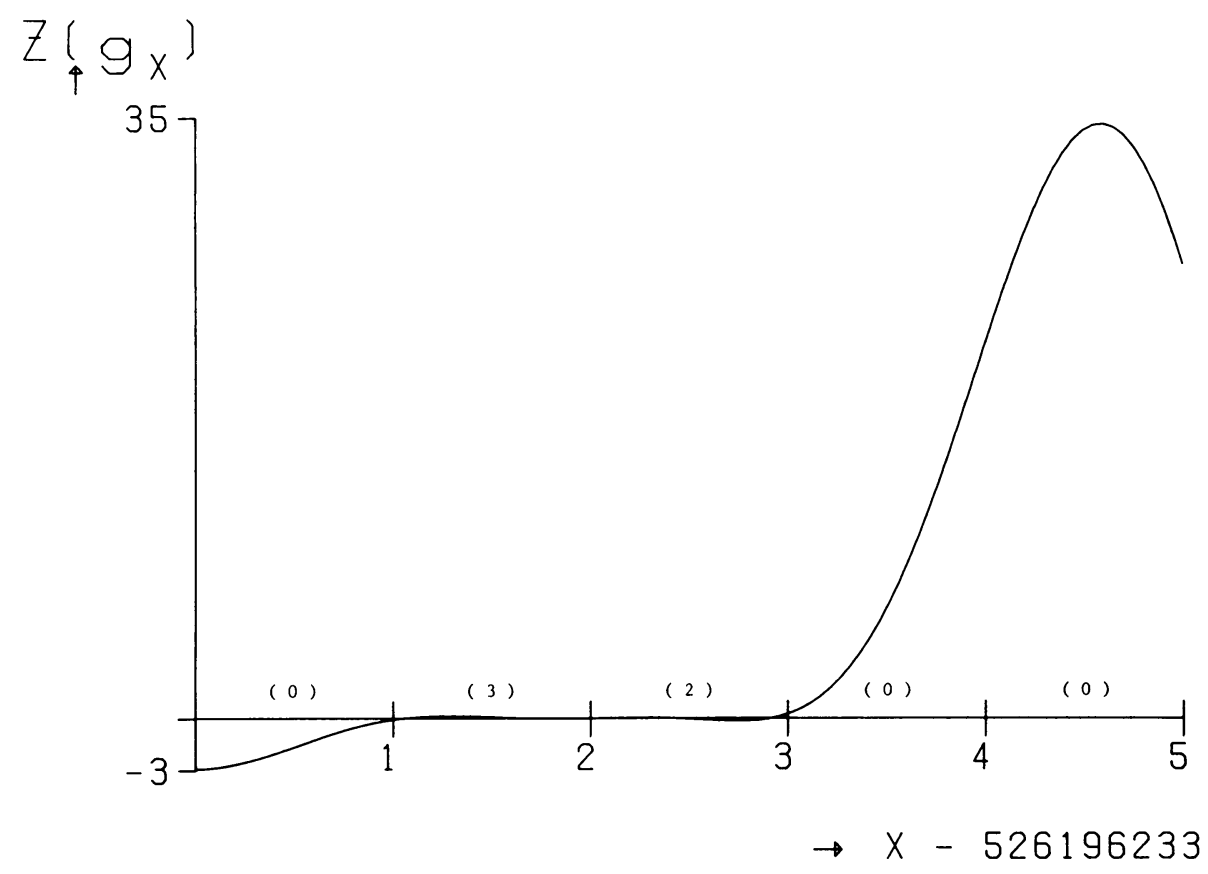

Figure 2

$B_{526,196,236}$, the first exception to Rosser's rule of length 2, type 8

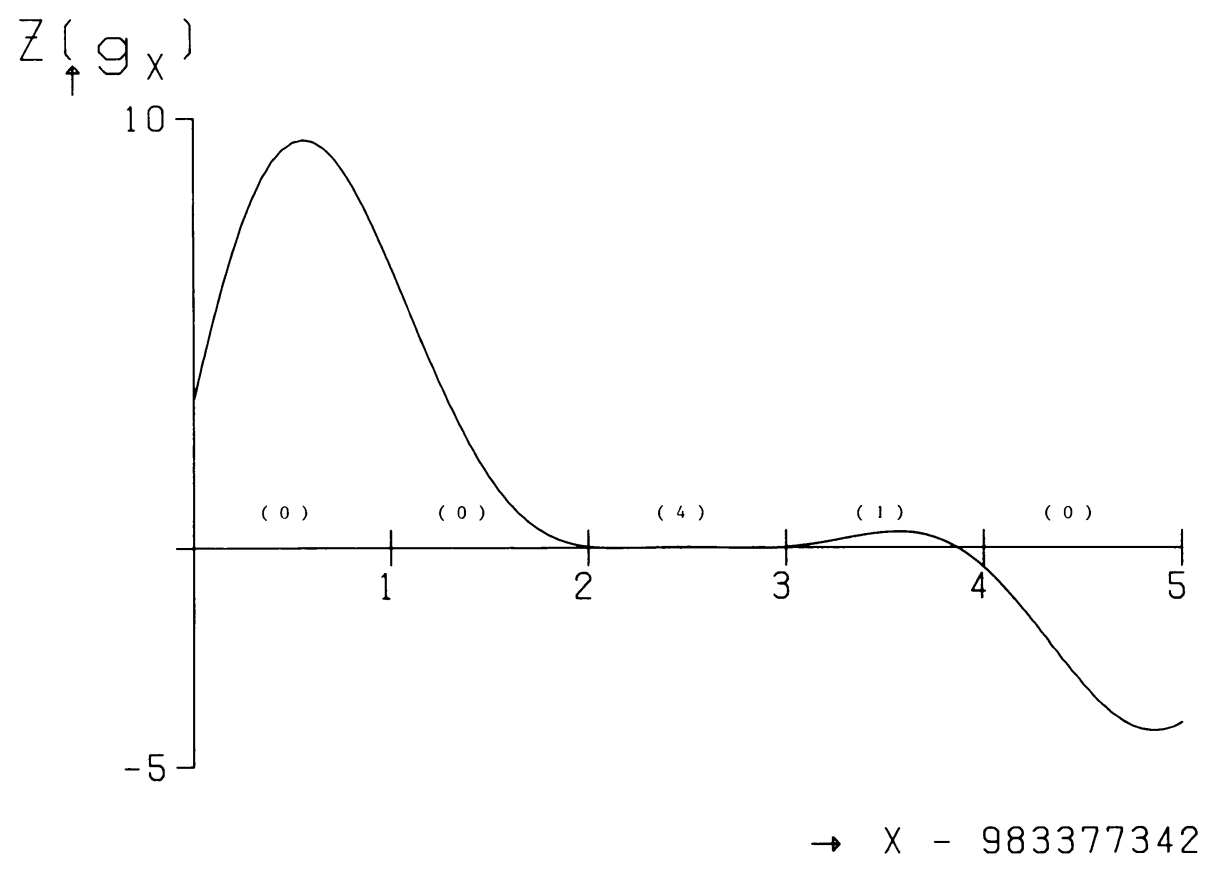

Figure 3

$B_{983,377,342}$, the first exception to Rosser's rule of length 2, type 9 


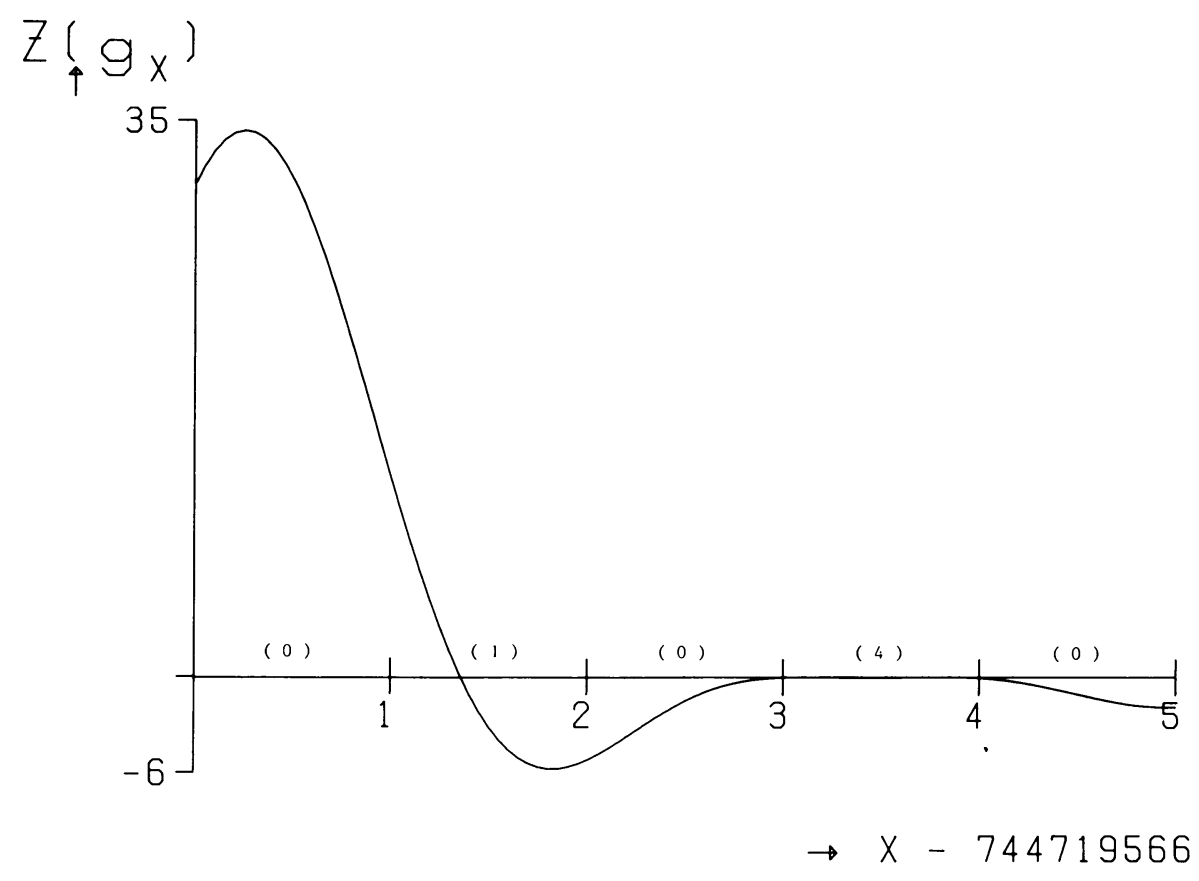

FIGURE 4

$B_{744,719,566}$, the first exception to Rosser's rule of length 3, type 3

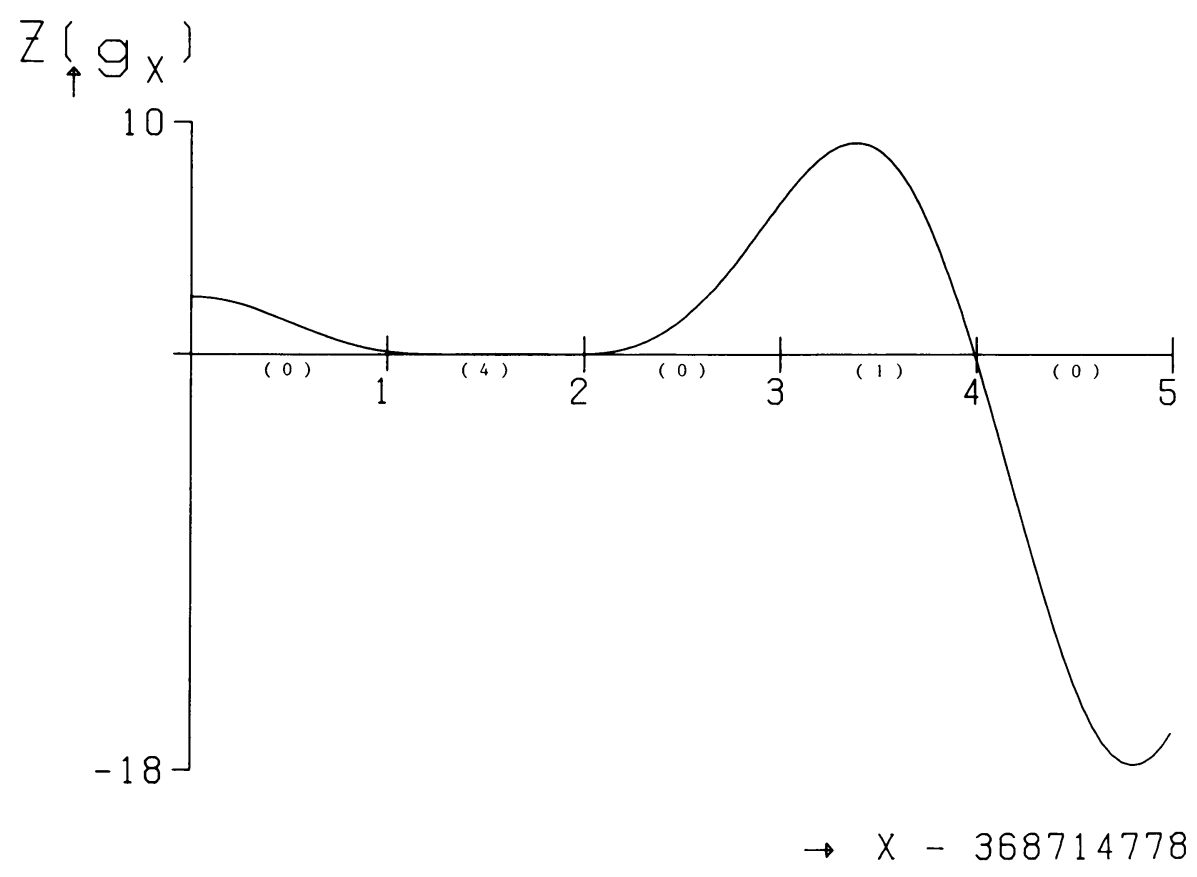

$B_{368,714,780}$, the first exception to Rosser's rule of length 3, type 4 


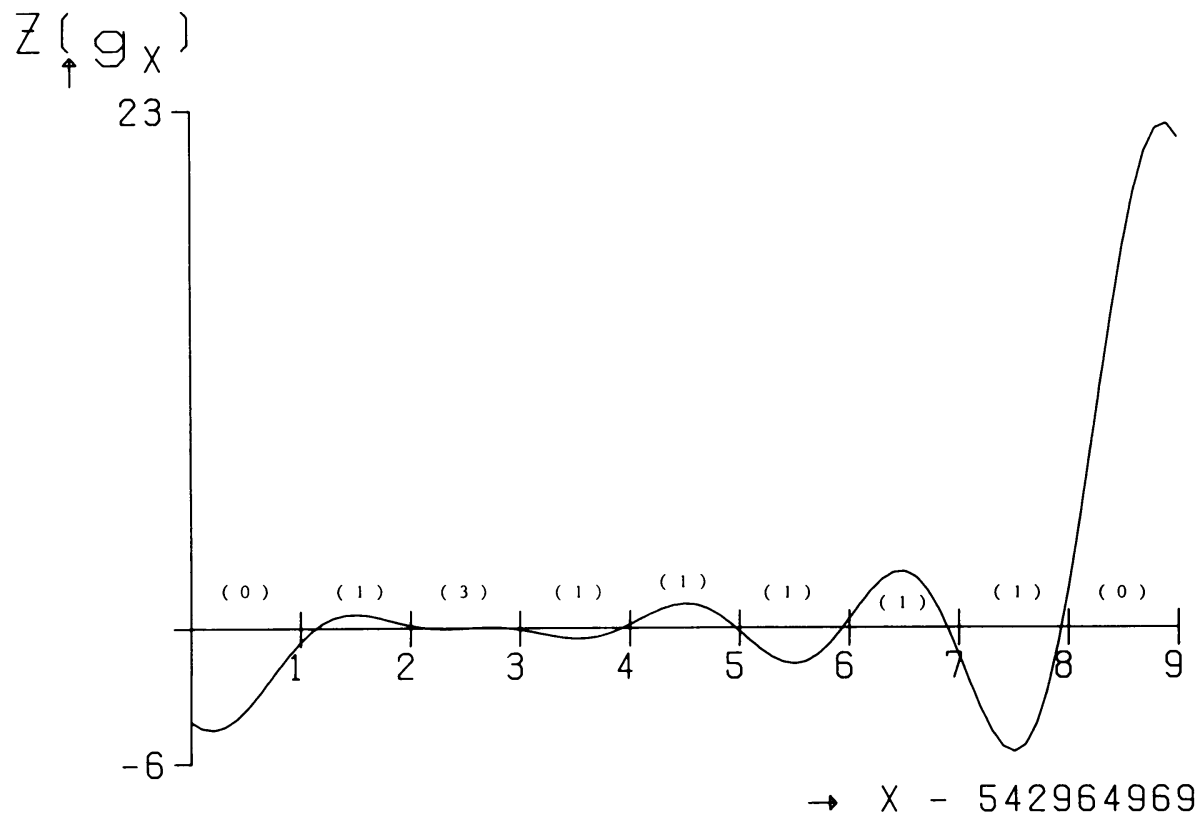

Figure 6

$B_{542,964,969}$, the first Gram block of length 9 (type $\left.(9,3)\right)$

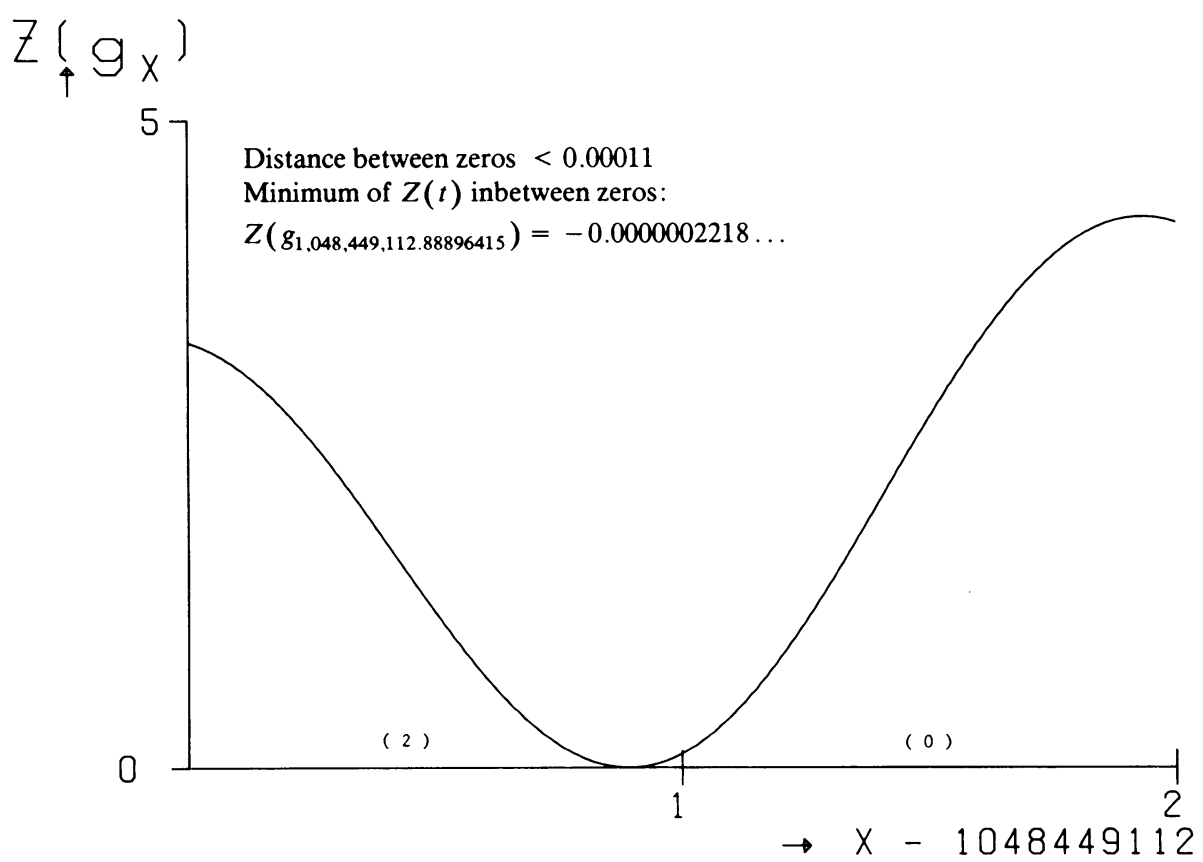

FIGURE 7

$B_{1,048,449,112}$, the Gram block (of length 2, type $(2,1)$ ) containing the closest observed pair of zeros 


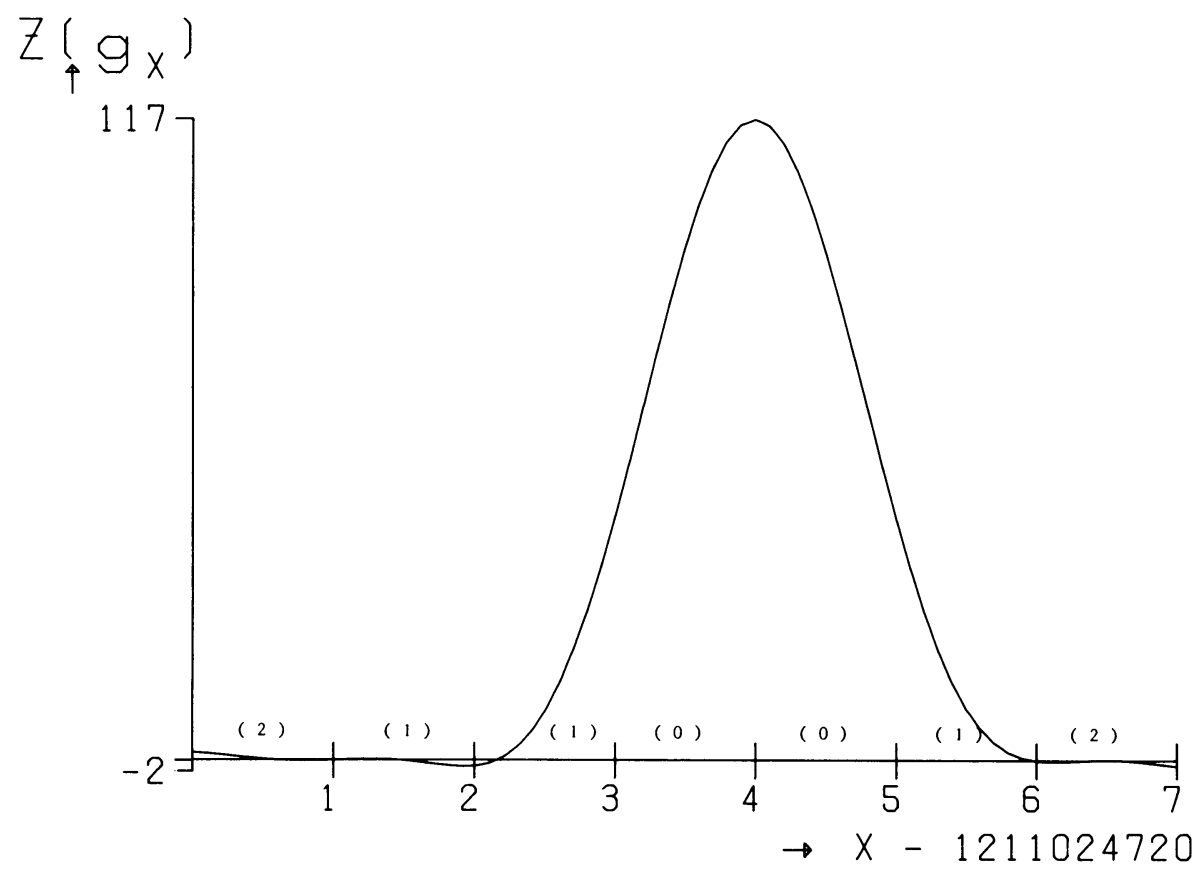

Figure 8

$Z(t)$ near its largest positive value found

(i.e., in the Gram point $g_{1,211,024,724}$ )

$Z_{4}\left(9_{x}\right)$

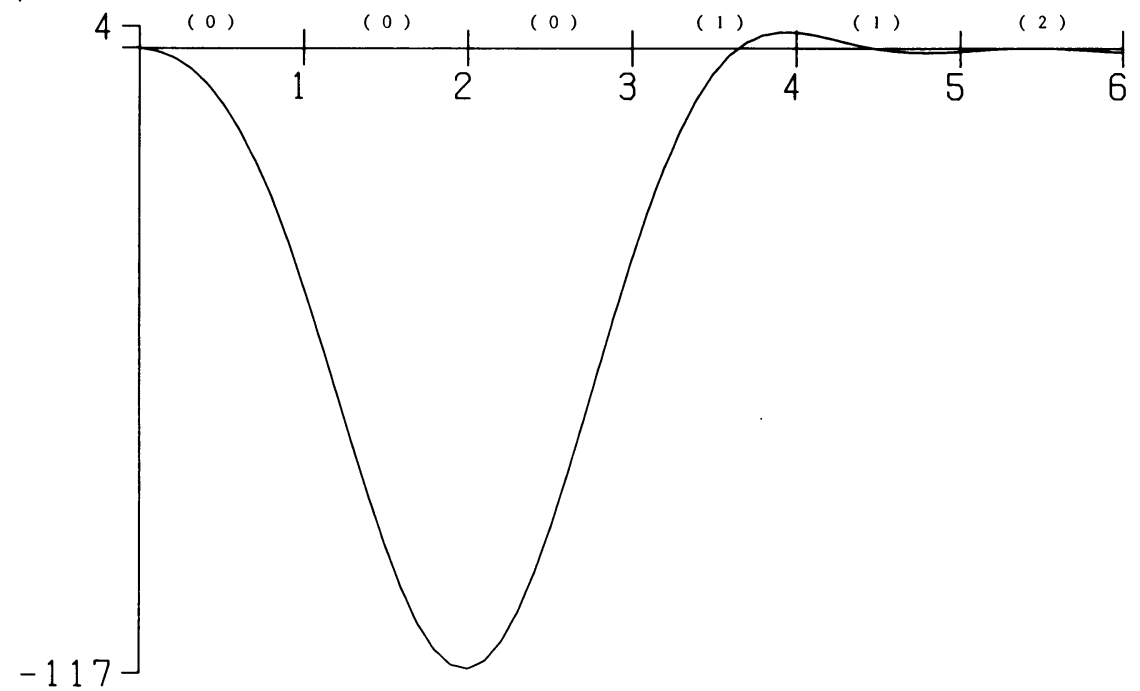

$\rightarrow \quad X-1381150787$

Figure 9

$Z(t)$ near its largest negative value found

(i.e., in the Gram point $g_{1,381,150,789}$ ) 
4. Discussion. Our statistical material suggests that the zeros of $Z(t)$ are distributed among the Gram intervals according to some hitherto unknown probabilistic law. E.g., the counts of the Gram blocks of lengths 3, 4, 5 and 6 of various types seem to tend to a certain (discrete) convex distribution (cf. the percentages in Tables 2 and 3) which depends on the length of the Gram block. It would be interesting to have a probabilistic model which could explain or at least support this phenomenon.

Several results in the literature (cf., [4], [5], [8], [10], [11], [12], [13]) have been derived from the existence of a number $A$, say, for which all complex zeros $\sigma+i t$ of $\zeta(s)$ with $|t|<A$ have real part $1 / 2$. Since our computations have increased this bound considerably, it might be worthwhile to trace the consequences of this new bound. We have not pursued this.

History has shown that proving the truth of the Riemann hypothesis is an extremely delicate task. Nevertheless, we hope that our computational results may stimulate interest and efforts which might lead to a better understanding of the Riemann hypothesis and of the distribution of the complex zeros of the Riemann zeta function.

Acknowledgments. We wish to thank Joke Blom for her help in preparing the figures. The computations on the CDC CYBER 205 computer were carried out shortly after its installation at the Academic Computer Centre Amsterdam (SARA). On the one hand, this was a big advantage since this allowed us to use a substantial portion of its computational capacity. On the other hand, some hardware problems prompted us to repeat several parts of our computations a number of times. We are much obliged to SARA and to CDC for the support during this stage of our work.

Added in Proof. As this paper is expected to be the last report of this kind from the CWI, we would like to summarize the contributions of the different co-authors. Large-scale computations to separate the zeros of the Riemann zeta function were started by Rosser, Yohe and Schoenfeld, and continued by Brent. JvdL saw possibilities to improve upon Brent's strategy to separate the zeros, and initiated the idea to go to $1,000,000,000$ zeros. He was supported and helped by HJJtR. HJJtR also took care of the verifications, classifications, tabulations and composition of the present paper. DTW optimized the programs for the machines involved, so that the goal could be reached, and, in fact, was reached much earlier than expected.

Centre for Mathematics and Computer Science

Kruislaan 413

1098 SJ Amsterdam, The Netherlands

1. R. P. Brent, "On the zeros of the Riemann zeta function in the critical strip," Math. Comp., v. 33, 1979, pp. 1361-1372.

2. R. P. Brent, J. van de Lune, H. J. J. Te Riele \& D. T. Winter, "On the zeros of the Riemann zeta function in the critical strip. II," Math. Comp., v. 39, 1982, pp. 681-688.

3. E. KarkoschKa \& P. Werner, "Einige Ausnahmen zur Rosserschen Regel in der Theorie der Riemannschen Zetafunktion,” Computing, v. 27, 1981, pp. 57-69.

4. I. KataI, “On oscillations of number-theoretic functions," Acta Arith., v. 13, 1967, pp. 107-122.

5. R. S. Lehman, “On the difference $\pi(x)-\operatorname{li}(x)$, , Acta Arith., v. 11, 1966, pp. 397-410.

6. J. VAn de Lune, H. J. J. TE Riele \& D. T. Winter, Rigorous High Speed Separation of Zeros of Riemann's Zeta Function, Report NW 113/81, Mathematical Centre, Amsterdam, October, 1981.

7. J. VAN DE LUNE \& H. J. J. TE RIELE, “On the zeros of the Riemann zeta function in the critical strip. III," Math. Comp., v. 41, 1983, pp. 759-767. 
8. J. PinTz, “On the sign changes of $M(x)=\sum_{n \leqslant x} \mu(n)$," Analysis, v. 1, 1981, pp. 191-195.

9. H. J. J. TE RIELE, D. T. WINTER \& J. VAN DE LUNE, Numerical Verification of the Riemann Hypothesis on the CYBER 205, in: Proc. International Supercomputer Applications Symp. (A. Emmen, ed.), North-Holland, Amsterdam, 1985, pp. 33-38.

10. J. B. Rosser \& L. SChoenfeld, "Approximate formulas for functions of prime numbers," Illinois J. Math., v. 6, 1962, pp. 64-94.

11. J. B. Rosser \& L. Schoenfeld, "Sharper bounds for the Chebyshev functions $\theta(x)$ and $\psi(x)$," Math. Comp., v. 29, 1975, pp. 243-269.

12. L. Schoenfeld, "Sharper bounds for the Chebyshev functions $\theta(x)$ and $\psi(x)$. II," Math. Comp., v. 30,1976, pp. $337-360$.

13. L. SCHOENFELD, "An improved estimate for the summatory function of the Moebius function," Acta Arith., v. 15, 1969, pp. 221-233.

14. D. T. WiNTER \& H. J. J. TE RIELE, "Optimization of a program for the verification of the Riemann hypothesis," Supercomputer, v. 5, 1985, pp. 29-32. 